\title{
De Novo Asymmetric Syntheses of SL0101 and Its Analogues via a Palladium-Catalyzed Glycosylation
}

\author{
Mingde Shan and George A. O'Doherty \\ Department of Chemistry, West Virginia University, Morgantown, WV 26506
}

\section{Abstract}

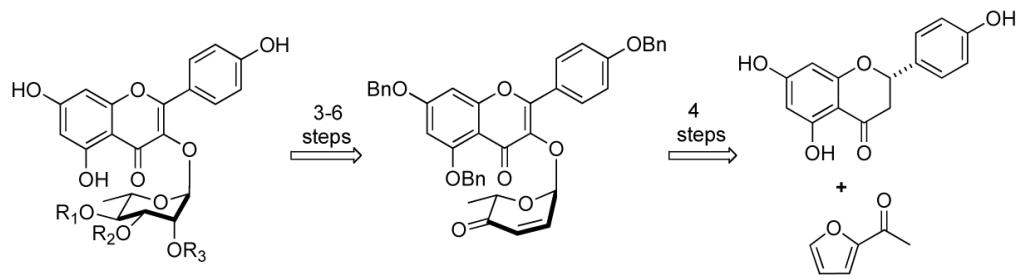

The enantioselective syntheses of naturally occurring kaempferol glycoside SL0101 (1a) and its analogues (1b-e), as well as their enantiomers have been achieved in 7 to 10 steps. The routes rely upon a diastereoselective palladium-catalyzed glycosylation, ketone reduction and dihydroxylation to introduce the rhamno-stereochemistry. The asymmetry of the sugar moiety of these flavone glycosides was derived from Noyori reduction of an acylfuran. An acetyl group shift from an axial (C-2) to equatorial position (C-3) under basic conditions was also described.

In an effort to find specific inhibitors of p90 Ribosomal S6 Kinase (RSK), Smith and Hecht screened an extensive collection of botanical extracts derived from rare plants. ${ }^{1}$ Using a dual high-throughput screen they found only one extract, which inhibited the RSK2 isoform (RSK2) without inhibiting the tyrosine kinase (FAK). The active extract was from a South American dogbane plant named Forsteronia refracta . More detailed bioactive fractionization revealed the active constituent to be a kaempferol glycoside, which was given the name SL0101 (Figure 1). ${ }^{1}$ SL0101 (1a) is a member of a class of acylated kaempferol L-rhamnosides which occur naturally with various degrees of acylation (e.g., 1a-e). ${ }^{2}$ SL0101 sans acetyl groups (1b) is also known as afzelin. ${ }^{2 \mathrm{a}}$ The kaempferol glycosides, like most flavonoids, have received a great deal of attention because they are believed to induce many positive biological effects. ${ }^{3}$

In addition to this unique activity, our interest in SL0101 (1a) was peaked by the report that it displayed some 150 times greater activity than the simple aglycon, kaempferol. Similarly, we were intrigued by the importance of the specific placement of acetyl groups on the L-rhamnose and its effect on the SAR of SL0101 (Figure 1). ${ }^{4}$ As part of an effort to elucidate the role of the sugar and acetyl portion of SL0101 to its activity, we decided to prepare both enantiomers of SL0101 (1a) and its analogues 1b-e (Figure 1).

Not long after the isolation and structure elucidation of SL0101 (1a), its first synthesis was reported by Professor Hecht. ${ }^{4}$ The Hecht synthesis derived the absolute and relative stereochemistry from rhamnose. In contrast, we were interested in the possibility of preparing

George.ODoherty@mail.wvu.edu.

Supporting Information Available: Experimental procedures and spectral data for all new compounds can be found in the Supporting Information. This material is available free of charge via the Internet at http://pubs.acs.org. 
all five members of this class of kaempferol glycosides (1a-e) via asymmetric catalysis. This de novo approach would have the additional advantage of preparing both the D-and the Lenantiomers for biological testing.

Recently we reported a diastereoselective palladium-catalyzed glycosylation reaction that used alcohols as nucleophiles and pyranones such as $\mathbf{4}$ as glycosyl donors. ${ }^{5} \mathrm{We}$ have also found several post glycosylation transforms, which subsequently install the desired sugar stereochemistry. ${ }^{6}$ This methodology also works well for other $N-, O$-nucleophiles, such as 6chloropurine/benzimidizole and phenol. ${ }^{7}$ In order to produce this class of interesting compounds for activity studies, we decided to apply this methodology toward the syntheses of the flavone glycosides, SL0101 (1a) and its analogues (1b-e). In addition to providing material for biological study, this effort should also allow us study flavon-3-ol as a nucleophile in the palladium-catalyzed glycosylation.

Retrosynthetically, we envisioned that pyranone 2 could be derived from a $\operatorname{Pd}(0)$-catalyzed glycosylation between flavonol 3 and pyranone 4 (Scheme 1). Subsequent application of $\mathrm{NaBH}_{4}$ reduction and an Upjohn dihydroxylation $\left(\mathrm{OsO}_{4} / \mathrm{NMO}\right)^{8}$ would install the mannostereochemistry. ${ }^{9}$ The selective introduction of the C-4 acetyl group should occur by introducing an acylation reaction between the $\mathrm{NaBH}_{4}$ reduction and dihydroxylation. All that would remain would be to differentiate the C-2 hydroxyl group from the C-3 hydroxyl group. For this, we planned to use a combination of selective orthoester hydrolysis 10 and acyl migration reactions. ${ }^{11}$ Since pyranone 4 has been prepared in either enantiomeric form, ${ }^{12}$ this procedure should be amenable to the preparation of both enantiomers of 1a-e. Herein we describe our successful efforts at the implementation of this strategy to this class of kaempferol glycosides (1a-e), which is noteworthy in that the various acetyl groups in 1a-e are installed without any hydroxyl protecting groups on the sugar.

Our synthesis started with the known perbenzylated kaempferol $\mathbf{3}$, which was synthesized from narringin $\mathbf{6}$ in three steps (Scheme 2). ${ }^{4}$ The glycosylation was carried out with flavonol $\mathbf{3}$ and L-pyranone 4 under catalysis of $2.5 \mathrm{~mol} \% \mathrm{Pd}_{2}(\mathrm{dba})_{3} \cdot \mathrm{CHCl}_{3}$ and $10 \mathrm{~mol} \%$ of $\mathrm{PPh}_{3}$ in $\mathrm{CH}_{2} \mathrm{Cl}_{2}$ at $0{ }^{\circ} \mathrm{C}$, which afforded pyranone 2 in $85 \%$ yield with complete $\alpha$-selectivity (Scheme 2). Reduction of the enone 2 by $\mathrm{NaBH}_{4}$ at $-78^{\circ} \mathrm{C}_{\text {in }} \mathrm{CH}_{2} \mathrm{Cl}_{2} / \mathrm{MeOH}$ resulted in allylic alcohol 7 in $73 \%$ yield with excellent diastereoselectivity ( $\mathrm{dr}>20: 1)$. The rhamno-stereochemistry in 8 was diastereoselectively introduced upon exposure of 7 to the Upjohn conditions $\left(\mathrm{OsO}_{4} /\right.$ NMO, 96\%). Debenzylation of 8 using Pearlman's catalyst (10\% Pd/C) in the presence of hydrogen gave kaempferol-3- $\alpha$-L-rhamnoside (1b) in $80 \%$ yield.

In addition to the unacylated rhamno-sugar $\mathbf{1 b}$, the peracylated sugar $\mathbf{1 c}$ could also be easily prepared in two steps from triol $\mathbf{8}$. Exhaustive acylation of the triol $\mathbf{8}$ with the excess acetic anhydride in presence of pyridine and 10\% DMAP gave triacetate 9 in $86 \%$ yield (Scheme 3). Debenzylation of triacetate 9 by hydrogen using Pearlman's catalyst $(10 \% \mathrm{Pd} / \mathrm{C})$ again produced kaempferol-3- $\alpha$-L-2",3",4"-O-triacetylrhamnoside (1c) in $86 \%$ yield.

The selective installation of the C-4 acetyl group in $\mathbf{1 d}$ was easily achieved without the need of additional protecting groups from the previously described allylic alcohol 7 (Scheme 2). In this route (Scheme 4), the $\mathrm{NaBH}_{4}$ reduction of enone $\mathbf{6}$ was followed by an acylation of the resulting allylic alcohol with acetic anhydride in the presence of pyridine and DMAP. This two-step procedure afforded acetate 10 in $70 \%$ overall yield. Once again, dihydroxylation using the Upjohn condition stereoselectively converted allylic acetate 10 into the rhamno-diol 11 in $77 \%$ yield. Global deprotection was accomplished under hydrogenolysis conditions by exposure of diol 11 to $1 \mathrm{~atm}$ of $\mathrm{H}_{2}$ in the presence of Pearlman's catalyst $(\mathrm{Pd} / \mathrm{C})$, which furnished kaempferol-3- $\alpha$-L-4"- $O$-acetylrhamnoside (1d) in $87 \%$ yield. 
Acylation of the C-2 axial hydroxyl group of diol 11 was selectively introduced using orthoester chemistry in excellent yield (99\%). ${ }^{6}$ Exposure of diol $\mathbf{1 1}$ to trimethyl orthoacetate in the presence of $10 \%$ - $\mathrm{TsOH}$ in $\mathrm{CH}_{2} \mathrm{Cl}_{2}$ followed by hydrolysis with excess $90 \% \mathrm{HOAc} / \mathrm{H}_{2} \mathrm{O}$ (Scheme 5). Once again, reductive debenzylation of 12 with hydrogen and $10 \% \mathrm{Pd} / \mathrm{C}$ produced kaempferol-3- $\alpha$-L-2",4"-O-diacetylrhamnoside (1e) in $88 \%$ yield.

In contrast to the selective C-2 acylation of the axial alcohol in $\mathbf{1 1}$ (Scheme 5), our synthesis of SL0101 required the selective acylation of the C-3 equatorial alcohol (Scheme 6). Unfortunately all of our attempts with $\mathrm{Ac}_{2} \mathrm{O} / \mathrm{Py}$ at various temperature only furnished mixtures of diacetate $\mathbf{1 3}$ and 12, as well as triacetate $\mathbf{9}(\sim 1: 1: 1)$. We next turned to the isomerization of the less stable axial C-2 acetate in $\mathbf{1 2}$ to the more stable equatorial C-3 acetate in $\mathbf{1 3}$.

All attempts to shift the axial acetyl group of diacetate $\mathbf{1 2}$ to the equatorial position by using $10 \mathrm{~mol} \% p$ - $\mathrm{TsOH}$ in $\mathrm{CH}_{2} \mathrm{Cl}_{2}$ at room temperature failed to give desired diacetate $\mathbf{1 3}$ (Scheme 6). In contrast, more promising results were seen with basic conditions. For instance, analysis of crude ${ }^{1} \mathrm{H}$ NMR of dilute toluene solutions of $\mathbf{1 2}$ with one equiv of DBU showed clean conversion to a 2:1 mixture of $\mathbf{1 3}$ and $\mathbf{1 2}$. In practice good yields of $\mathbf{1 3}(62 \%)$ could be obtained along with recovered starting material (34\%) after $\mathrm{SiO}_{2}$ chromatography. Finally, debenzylation of $\mathbf{1 3}$ under the similar condition as before produced SL0101 (1a) in 91\% yield. Our synthetic products (1a-e) were physically and spectroscopically identical to the isolated natural materials in terms of melting point, optical rotation, $\mathrm{R}_{f},{ }^{1} \mathrm{H}$ NMR, ${ }^{13} \mathrm{C}$ NMR and MS. 2,4

In conclusion, a divergent and highly enantio- and diastereoselective procedures for the preparation of naturally occurring SL0101 (1a) as well as four kaempferol rhamnoside analogues (1)-e) has been developed. This approach provides either enantiopode of kaempferol glycosides 1a-e without protecting any of the sugar hydroxyl groups. Our approach relied upon a diastereoselective palladium(0)-catalyzed glycosylation followed by a sequence of reduction/ dihydroxylation reaction, as well as acylation. An acetyl group shift from an axial position to an equatorial position provided an alternative way for selective acylation of the equatorial hydroxyl group of a cis-diol in carbohydrate chemistry. The evaluation of the biological activities of these flavone glycosides is in progress.

\section{Supplementary Material}

Refer to Web version on PubMed Central for supplementary material.

\section{Acknowledgment}

We thank the NIH (GM63150) and NSF (CHE-0415469) for their generous support of our research program. Funding for a $600 \mathrm{MHz}$ NMR and an LTQ-FT Mass Spectrometer by the NSF-EPSCoR (\#0314742) is also gratefully acknowledged.

\section{References}

1(a). Smith JA, Poteet-Smith CE, Xu Y, Errington TM, Hecht SM, Lannigan DA. Cancer Res 2005;65:1027-1034. [PubMed: 15705904] (b) Xu Y, Smith JA, Lannigan DA, Hecht SM. Bioorg. Med. Chem 2006;14:3974-3977. [PubMed: 16524738]

2(a). For the isolation of 1a-b see ref. 1b and:Matthes HWD, Luu B, Ourisson G. Phytochem 1980;19:2643-2650.For 1b, see: (b) Kaouadji M. Phytochem 1990;29:2295-2297. For 1b and 1d, see: (c) Masuda T, Jitoe A, Kato S, Nakatani N, Phytochem. 1991;30:2391-2392. For 1a and 1e, see: (d) Nakatani N, Jitoe A, Masuda T. Agric. Biol. Chem 1991;55:455-460. For 1c see: (e) Usia T, Iwata H, Hiratsuka A, Watabe T, Kadota S, Tezuka Y. J. Nat. Prod 2004;67:1079-1083. [PubMed: 15270556] For 1b, see: (f) Deng J-Z, Marshall R, Jones SH, Johnson RK, Hecht SM. J. Nat. Prod 2002;65:1930-1932. [PubMed: 12502343] 
3(a). Muir SR, Collins GJ, Robinson S, Hughes S, Bovy A, Ric De Vos CH, van Tunen AJ, Verhoeyen ME. Nat. Biotechnol 2001;19:470-474. [PubMed: 11329019] (b) Hertog MGL, Feskens EJM, Hollman PCH, Katan MB, Kromhout D. Lancet 1993;342:1007-1011. [PubMed: 8105262]

4. Maloney DJ, Hecht SM. Org. Lett 2005;7:1097-1099. [PubMed: 15760148]

5(a). Babu RS, O’Doherty GA. J. Am. Chem. Soc 2003;125:12406-12407. [PubMed: 14531673] (b) Babu RS, Zhou M, O'Doherty GA. J. Am. Chem. Soc 2004;126:3428-3429. [PubMed: 15025462]

6(a). Harris JM, Keranen MD, O’Doherty GA. J. Org. Chem 1999;64:2982-2983. [PubMed: 11674384] (b) Harris JM, Keranen MD, Nguyen H, Young VG, O’Doherty GA. Carbohydr. Res 2000;328:1736. [PubMed: 11005573]

7(a). Guo H, O’Doherty GA. Org. Lett 2005;7:3921-3924. [PubMed: 16119932] (b) Guppi SR, Zhou M, O’Doherty GA. Org. Lett 2006;8:293-296. [PubMed: 16408898] (c) Babu RS, Guppi SR, O'Doherty GA. Org. Lett 2006;8:1605-1608. [PubMed: 16597121]

8. VanRheenen V, Kelly RC, Cha DY. Tetrahedron Lett 1976;17:1973-1976.

9. According to carbohydrate nomenclature, rhamnose is 6-deoxymannose

10(a). For the selective acylation of an axial alcohol see: ref. 6 and King JF, Allbutt AD. Can. J. Chem 1970;48:1754-1769. (b) Lowary TL, Hindsgaul O. Carbohydr. Res 1994;251:33-67. [PubMed: 8149379]

11(a). Doerschuk AP. J. Am. Chem. Soc 1952;74:4202-4203. (b) Pettit GR, Cragg GM, Suffness M. J. Org. Chem 1985;50:5060-5063.

12. Pyranones such as $\mathbf{4}$ and its enantiomer $\boldsymbol{e n t} \mathbf{- 4}$ can be prepared in three steps from achiral acylfurans such as $\mathbf{5}$ in either enantiomeric form $(\mathrm{D} / \mathrm{L})$. The pyranone asymmetry is derived from a Noyori reduction; see ref 5b, 7a and: Li M, Scott JG, O'Doherty GA. Tetrahedron Lett 2004;45:1005-1009.<smiles>CC(C)O[C@H]1C=CC(=O)[C@@H](C)O1</smiles> 


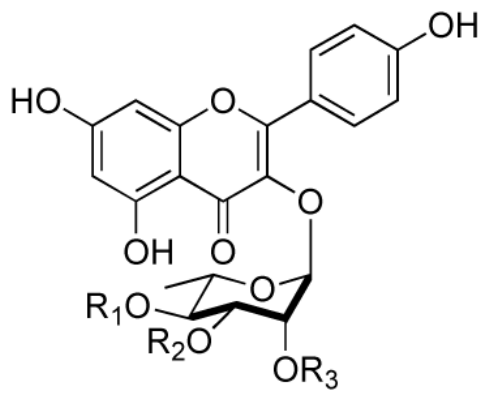

\begin{tabular}{ccccc}
\hline & $\mathrm{R}_{1}$ & $\mathrm{R}_{2}$ & $\mathrm{R}_{3}$ & $\mathrm{IC}_{50}(\mathrm{Rsk} 2)$ \\
\hline $\mathbf{1 a}$ & $\mathrm{Ac}$ & $\mathrm{Ac}$ & $\mathrm{H}$ & $89 \mathrm{nM}$ \\
$\mathbf{1 b}$ & $\mathrm{H}$ & $\mathrm{H}$ & $\mathrm{H}$ & ------- \\
$\mathbf{1 c}$ & $\mathrm{Ac}$ & $\mathrm{Ac}$ & $\mathrm{Ac}$ & ------ \\
$\mathbf{1 d}$ & $\mathrm{Ac}$ & $\mathrm{H}$ & $\mathrm{H}$ & $189 \mathrm{nM}$ \\
$\mathbf{1 e}$ & $\mathrm{Ac}$ & $\mathrm{H}$ & $\mathrm{Ac}$ & $580 \mathrm{nM}$
\end{tabular}

Figure 1.

Kaempferol glycoside SL0101 (1a) and its analogues (1b-e), and their Rsk2 inhibitory activities. 

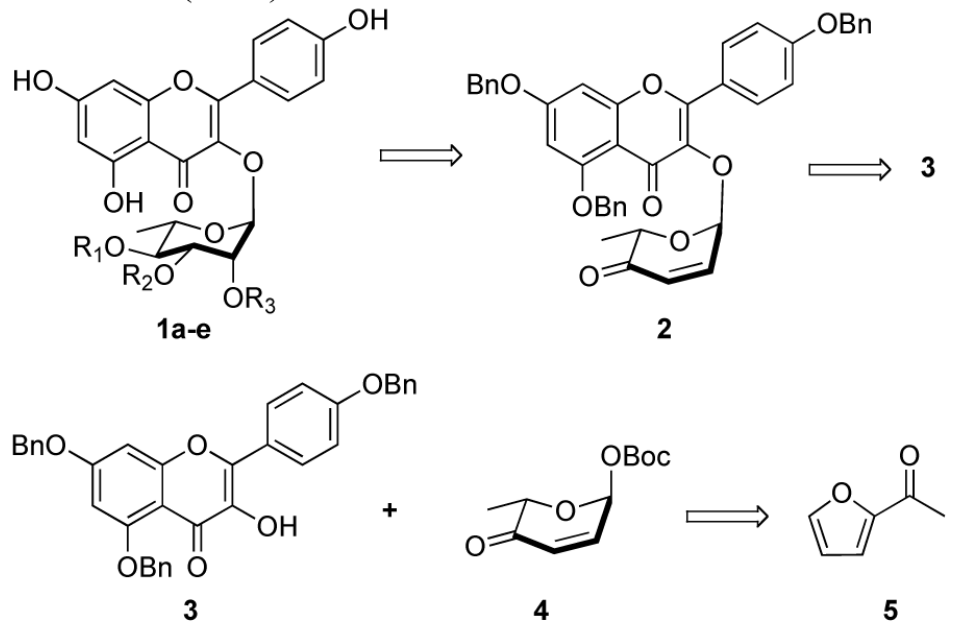

Scheme 1.

Retrosynthetic analysis of kaempferol rhamnosides (1a-e) 
<smiles>O=C1C[C@H](c2ccc(O)cc2)Oc2cc(O)cc(O)c21</smiles><smiles>[R19]CCCCOc1cc(OC)c2c(=O)c(O)c(-c3ccc(OCc4ccccc4)cc3)oc2c1</smiles>

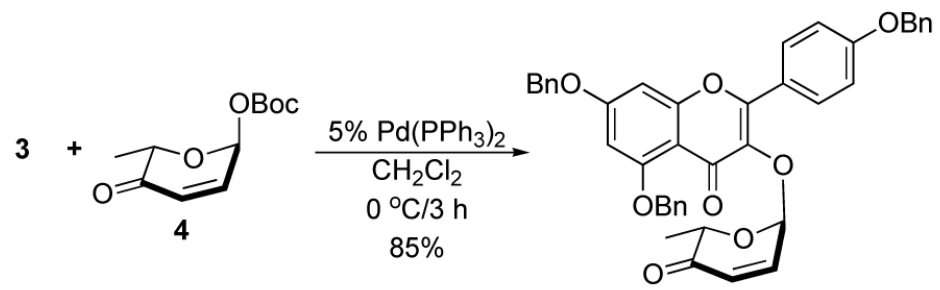

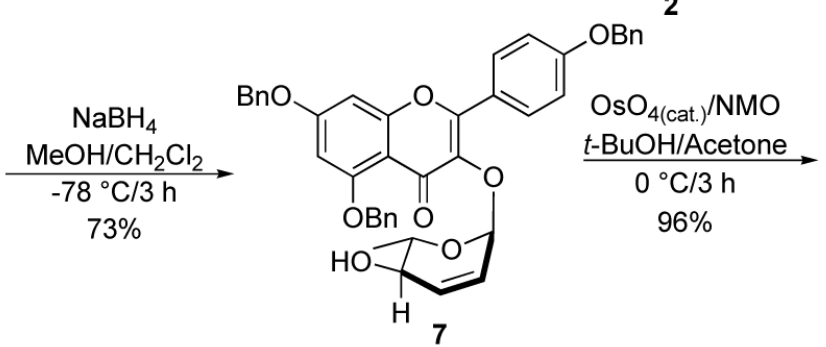

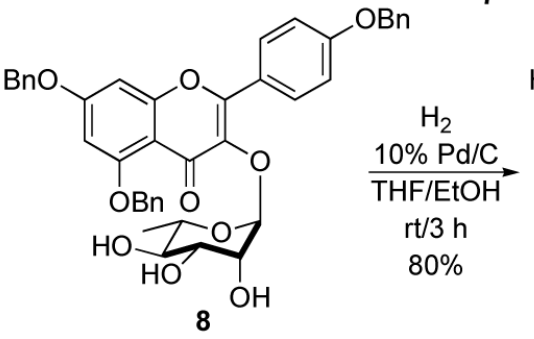<smiles>O=C1OC2=C(c3ccc(O)cc3)C(O)C(O)C(O)C(O2)Oc2cc(O)cc(O)c21</smiles>

Scheme 2.

Synthesis of kaempferol-3- $\alpha$-L-rhamnoside (1b). 

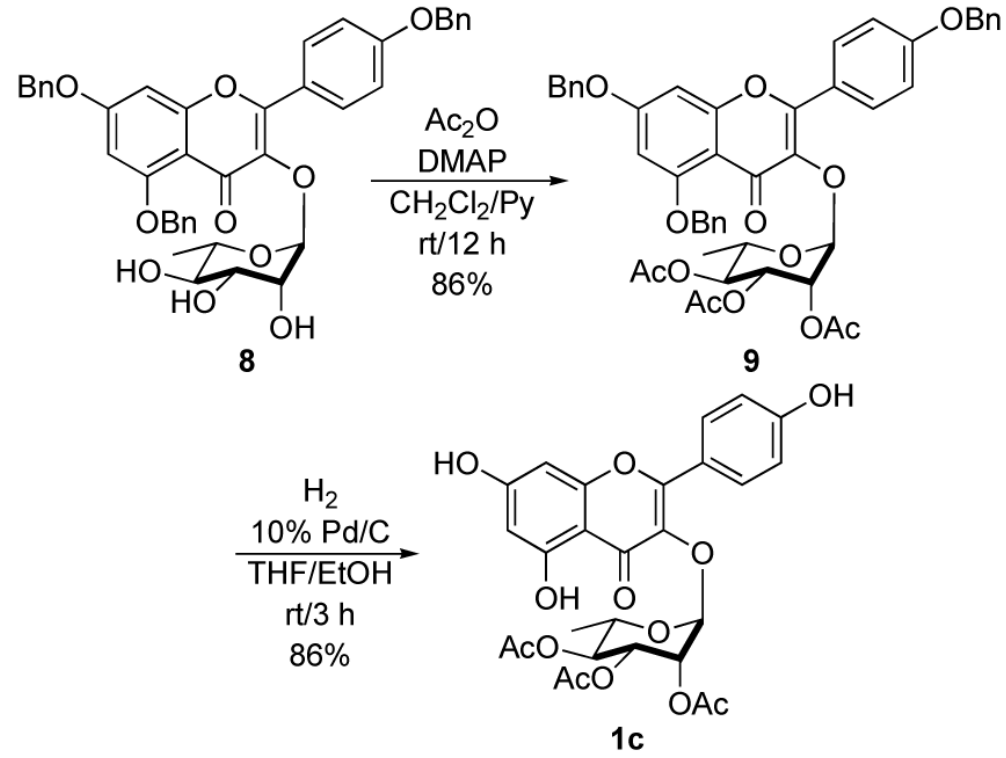

Scheme 3.

Synthesis of kaempferol-3- $\alpha-\mathrm{L}-2^{\prime \prime}, 3^{\prime \prime}, 4^{\prime \prime}-\mathrm{O}$-triacetylrhamnoside (1c). 


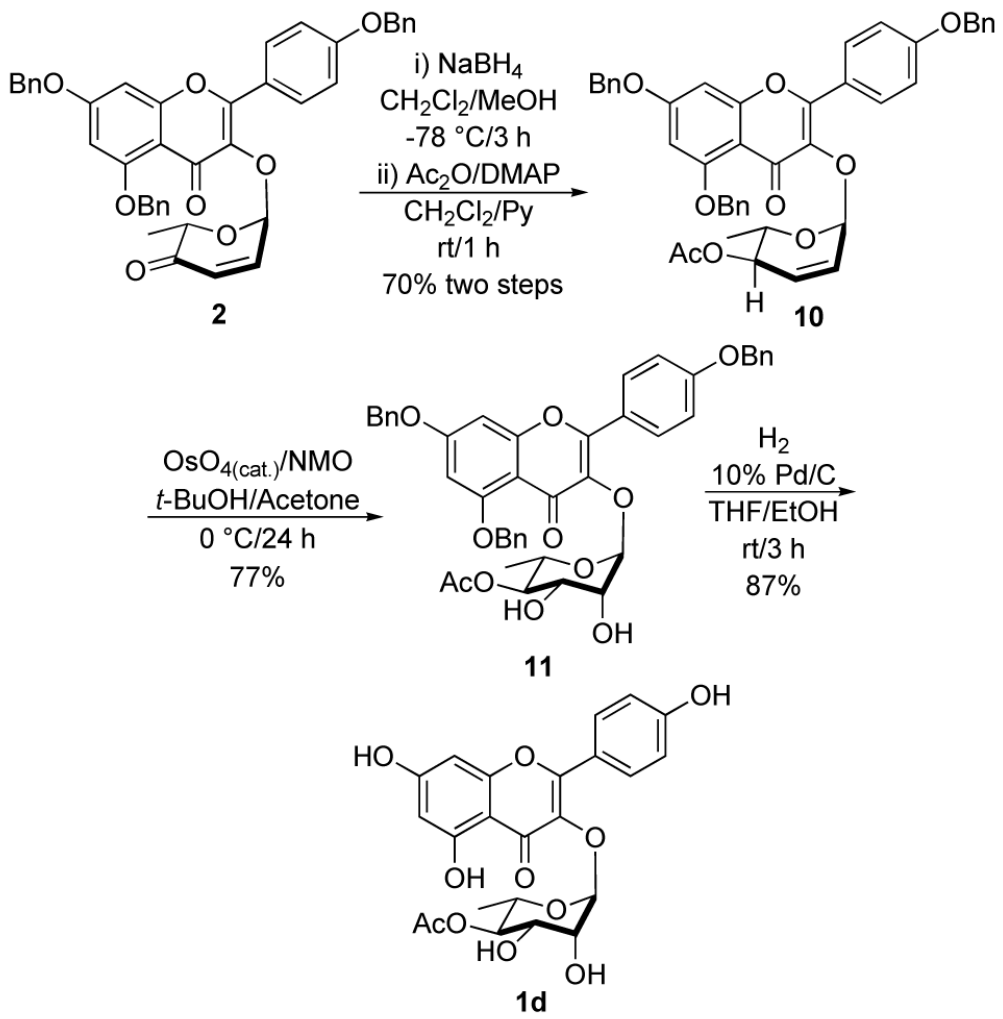

Scheme 4.

Synthesis of kaempferol-3- $\alpha-\mathrm{L}-4{ }^{\prime \prime}-O$-acetylrhamnosid(1d). 


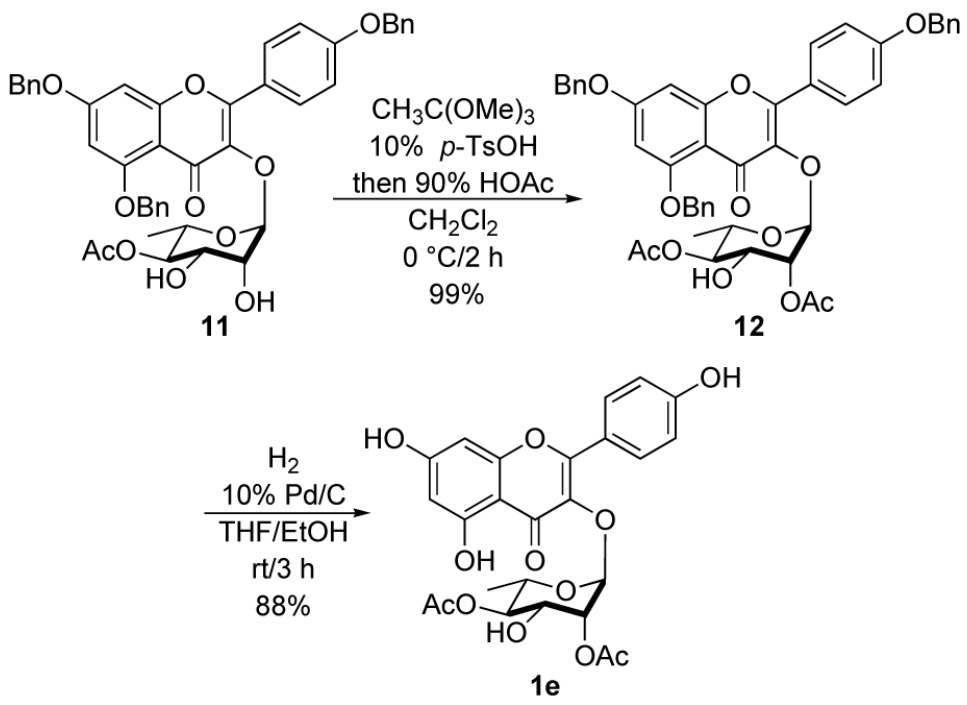

Scheme 5.

Synthesis of kaempferol-3- $\alpha$-L-2",4"-O-diacetylrhamnoside (1e). 


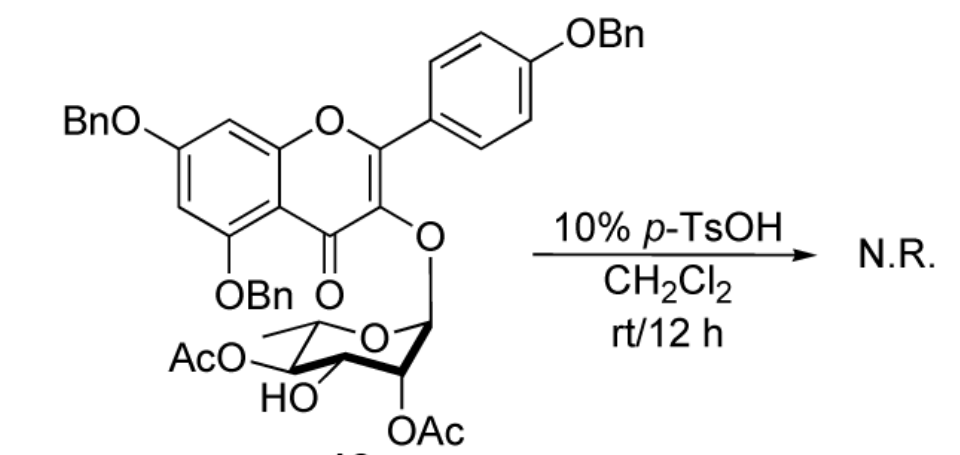

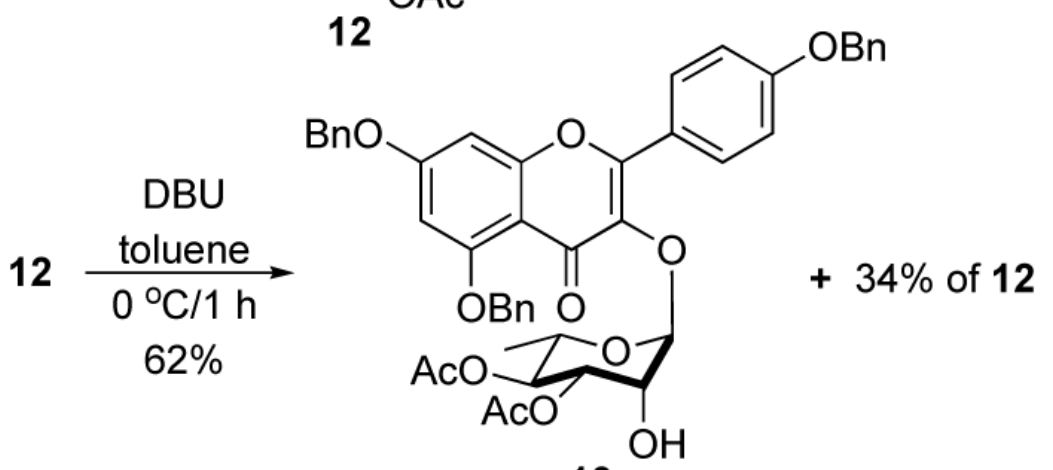

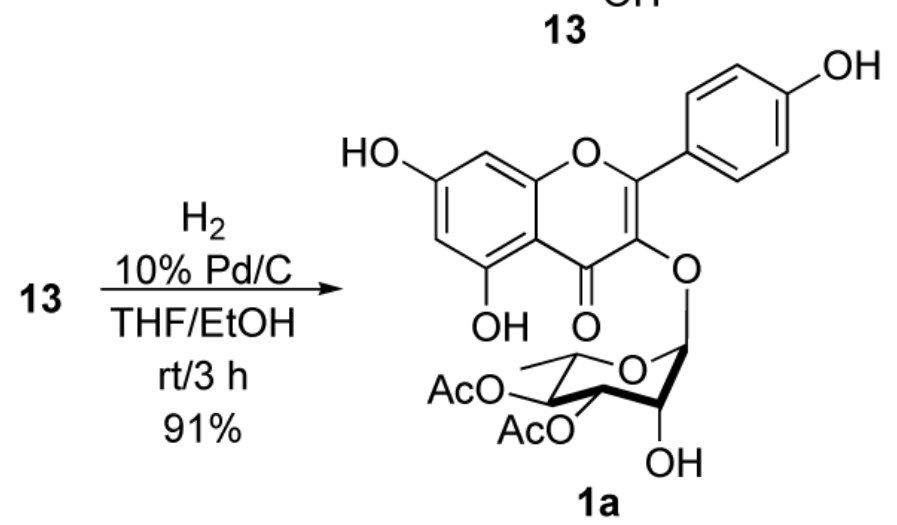

Scheme 6.

Synthesis of SL0101 (1a) 